\title{
On Development of Fuzzy Controller: The Case of Gaussian and Triangular Membership Functions
}

\author{
Vincent O. S. Olunloyo, Abayomi M. Ajofoyinbo, Oye Ibidapo-Obe \\ Department of Systems Engineering, Faculty of Engineering Complex, University of Lagos, Lagos, Nigeria. \\ Email: vosolunloyo@hotmail.com,yomi_ajofoyinbo@yahoo.co.uk, oyeibidapoobe@yahoo.com \\ Received September $30^{\text {th }}, 2011$; revised October $31^{\text {st }}, 2011$; accepted November $16^{\text {th }}, 2011$.
}

\begin{abstract}
In recent years, the use of Fuzzy set theory has been popularised for handling overlap domains in control engineering but this has mostly been within the context of triangular membership functions. In actual practice however, such domains are hardly triangular and in fact for most engineering applications the membership functions are usually Gaussian and sometimes cosine. In an earlier paper, we derived explicit Fourier series expressions for systematic and dynamic computation of grade of membership in the overlap and non-overlap regions of triangular Fuzzy sets. In another paper, we extended the methodology to cover cases of cosine, exponential and Gaussian Fuzzy sets by presenting explicit Fourier series representation for encoding fuzziness in the overlap and non-overlap domains of Fuzzy sets. This current paper presents the development of a "Fuzzy Controller" device, which incorporates the formal mathematical representation for computing grade of membership of Gaussian and triangular Fuzzy sets. It is shown that triangular approximation of Gaussian membership function in Fuzzy control can lead to wrong linguistic classification which may have adverse effects on operational and control decisions. The development of the Fuzzy controller demonstrates that the proposed technique can indeed be incorporated in engineering systems for dynamic and systematic computation of grade of membership in the overlap and non-overlap regions of Fuzzy sets; and thus provides a basis for the design of embedded Fuzzy controller for mission critical applications.
\end{abstract}

Keywords: Fuzzy Controller, Triangular, Gaussian, Fourier Series Representation, Membership Functions

\section{Introduction}

The key elements in human thinking are not numbers, but labels of Fuzzy sets, viz: classes of objects in which the transition from membership to non-membership is gradual rather than abrupt (Zadeh [1]). Fuzzy logic has found applications for control and analysis purposes, as for example recorded in the work of Bellman and Zadeh [2], Berenji and Khedar [3]. Ruan and Fantoni [4] also reported industrial applications of Fuzzy logic. Olunloyo and Ajofoyinbo [5] applied hybrid Fuzzy-stochastic methodology for maintenance optimization. Araujo, Sandri and Macau [6], Marinke and Araujo [7], and Moura, Rodrigues and Araujo [8] presented some other industrial applications of Fuzzy systems/logic most of which are related to thermal-vacuum processes, usually encountered in particular, in the qualification of space devices. Savkovic [9] studied Fuzzy logic theory and applied it to the process control system. Ji and Wang [10] developed an adaptive Neural Fuzzy Controller for active vibration suppression in flexible structures. Researchers generally treat the overlap region as intersection or union of two or more Fuzzy sets and have invoked the Min and Max operators, respectively, as needed. Olunloyo, Ajofoyinbo and Badiru [11] proposed an algorithm for the treatment of overlap of adjoining Fuzzy sets based on partitioned grids. In view of the importance of this Fuzzy overlap region, especially where there is need to monitor and ensure smooth transition between the adjoining Fuzzy sets in relation to the design of mission critical applications, Olunloyo and Ajofoyinbo [12] proposed an alternative approach for computing membership function based on the Fourier series representation of the envelope of the Fuzzy patch. In the literature, for example, as in the work of King and Mamdani [13], and Zimmermann [14], most control applications use triangular and trapezoidal profiles for membership functions. However, such triangular or trapezoidal assumptions, in most applications are generally poor approximations of the prevailing Gaussian membership function that governs most engineering processes. The Gaussian membership function applies in engineering problem domain, especially for 
engineering measurements; as it gives actual representation at every point.

According to Ross [15], membership function essentially embodies all fuzziness in a particular Fuzzy set, and its description is the essence of a Fuzzy property or operation. Watanabe [16] asserted that the statistical techniques for determining membership functions fall into two broad categories viz: use of frequencies and direct estimation. The two methods were analysed by Turksen [17] when he reviewed the various methods and their methodology for implementation. The determination of membership function can also be categorized as either being manual or automatic. The automatic generation of membership function emphasises the use of modern soft computing techniques (in particular Genetic Algorithm and Neural Networks). Meredith, Karr and Krishnakumar [18] applied Genetic Algorithm (GA) to the fine tuning of membership functions in a Fuzzy logic controller for a helicopter. Karr [19] applied GA to the design of Fuzzy logic controller for the Cart Pole problem. Lee and Takagi [20] also tackled the Cart problem. In their case, they took a holistic approach by using GA to design the whole system (determination of the optimal number of rules as well as the membership functions). Moreover, Ross [21] reported on six methods for developing membership functions namely: intuition, inference, rank ordering, neural networks, genetic algorithm and inductive reasoning. The manual and automatic techniques for determining membership functions of Fuzzy sets are nonsystematic and suffer from certain deficiencies. On the one hand, most of the existing automatic techniques are heuristic in nature; which implies that different values can be obtained for same input values presented at different times. On the other hand, the manual techniques suffer from the deficiency that they rely on subjective interpretation of words and the peculiarities of the engaged human expert.

By analyzing the nature of the overlap patches defined by the intersection and union of a typical grade of membership function for a linguistic variable, it is shown that the resultant signal does fall into the class of functions for which a Fourier series representation can be written. The problem then is to construct such a series and compute the corresponding coefficients. Furthermore, in order to align the results with the properties of membership functions, some element of normalization and standardization is introduced. To be more specific, starting with triangular Fuzzy sets, Olunloyo, Ajofoyinbo and Badiru [22] formulated explicit Fourier series representation for computing the grade of membership in the overlap and non-overlap regions. Ajofoyinbo [23] derived explicit Fourier series expressions for encoding fuzziness in the overlap and non-overlap domains of membership functions of different Fuzzy sets. This methodology was extended by obtaining explicit Fourier series expressions for computing the union and intersection of the Gaussian, cosine and exponential Fuzzy sets. In [24], Olunloyo, Ajofoyinbo and Ibidapo-Obe presented an implementation of embedded "Fuzzy Controller" via simulation. In the current work, the development of Fuzzy controller based on Fourier series representation for computing grade of membership of Gaussian and triangular Fuzzy sets are presented. This paper also investigates the performance of Fuzzy controller based on Gaussian and triangular membership functions, in classifying data values in the universe of discourse. The remainder of this paper is organized as follows: Problem formulation is presented in Chapter 2. This is followed by Systems design and implementation in Chapter 3. Discussion of sample results is presented in Chapter 4. Chapter 5 concludes the paper.

\section{Problem Formulation}

Fundamental conditions for Fourier series representation are: 1) Function must be periodic, 2) Function must have finite number of discontinuities, and 3) Function must be bounded.

We note that the universe of discourse in a Fuzzy plane consists of one or more data points. Each of the data points in a given universe of discourse has some form of data distribution around it in the form of some distribution profile, whether Gaussian, exponential, triangular or any other. Since all data points in the universe of discourse would have same form of data distribution around every data point, we could therefore derive an explicit Fourier series expression for the envelope of the Fuzzy patch since we can be assured of the repetition of the assumed distribution pattern around each data point. Moreover, in as much as the distribution around the data points has same shape, then appropriate normalisation can be introduced to transform the union and intersection of such Fuzzy sets into functions that are amenable to Fourier series representation. Although various functional profiles of membership functions could be used, the triangular and trapezoidal have in the past served as approximations of the others in the first instance. In fact, the trapezoidal form can, further, be approximated by the triangular form since the end-points of the 'tolerance' interval in a trapezoidal distribution have the same grade of membership and could therefore be assigned a point value that represents the peak of the triangular profile. In Sections 2.1 and 2.2 below, we present Fourier series representation for computing union and intersection of Gaussian and triangular Fuzzy sets respectively. 


\subsection{Fourier Series Representation for Gaussian Membership Function}

The membership function of union of Gaussian Fuzzy sets is computed as follows:

$$
f(\bar{x})=\frac{a_{0}}{2}+\sum_{k=1}^{n}\left(a_{k} \cos (k w \bar{x})+b_{k} \sin (k w \bar{x})\right)
$$

where

$$
\frac{a_{0}}{2}=\frac{1}{8 \pi^{3}}\left(\int_{0}^{\pi} \mathrm{e}^{-\left(\frac{1}{2} \bar{x}^{2}+2\left(\frac{-2 \pi}{6}\right) \bar{x}+\frac{4 \pi^{2}}{18}\right)} \mathrm{d} \bar{x}+\int_{\pi}^{2 \pi} \mathrm{e}^{-\left(\frac{1}{2} \bar{x}^{2}+2\left(\frac{-4 \pi}{6}\right) \bar{x}+\frac{16 \pi^{2}}{18}\right)} \mathrm{d} \bar{x}\right)
$$

Recall from Abramowitz and Stegun [25]:

$$
f(t)=\int \mathrm{e}^{-\left(a t^{2}+2 b t+c\right)} \mathrm{d} t=\frac{1}{2} \sqrt{\frac{\pi}{a}} * \mathrm{e}^{\frac{b^{2}-a c}{a}} * \operatorname{erf}\left(\sqrt{a} * t+\frac{b}{\sqrt{a}}\right)+\text { Const }
$$

Thus,

$$
\begin{aligned}
\frac{a_{0}}{2}=\frac{1}{8 \pi^{3}}\left\{0.5 * \sqrt{2 \pi}\left[\operatorname{erf}\left(\sqrt{0.5} * \pi+\frac{\left(\frac{-2 \pi}{6}\right)}{\sqrt{0.5}}\right)-\operatorname{erf}\left(\frac{\left(\frac{-2 \pi}{6}\right)}{\sqrt{0.5}}\right)\right]\right. \\
\left.+0.5 * \sqrt{2 \pi}\left[\operatorname{erf}\left(\sqrt{0.5} * 2 \pi+\frac{\left(\frac{-4 \pi}{6}\right)}{\sqrt{0.5}}\right)-\operatorname{erf}\left(\sqrt{0.5} * \pi+\frac{\left(\frac{-4 \pi}{6}\right)}{\sqrt{0.5}}\right)\right]\right\}
\end{aligned}
$$

From Equation (4), we define $I_{1}$ and $I_{2}$ as:

$$
I_{1}=0.5 \sqrt{2 \pi} *\left(\operatorname{erf}\left(\sqrt{0.5} * \pi+\frac{\left(\frac{-2 \pi}{6}\right)}{\sqrt{0.5}}\right)-\operatorname{erf}\left(\frac{\frac{-2 \pi}{6}}{\sqrt{0.5}}\right)\right)
$$

and

$$
I_{2}=0.5 \sqrt{2 \pi} *\left(\operatorname{erf}\left(\sqrt{0.5} * 2 \pi+\frac{\left(\frac{-4 \pi}{6}\right)}{\sqrt{0.5}}\right)-\operatorname{erf}\left(\sqrt{0.5} * \pi+\frac{\left(\frac{-4 \pi}{6}\right)}{\sqrt{0.5}}\right)\right)
$$

We compute coefficients $a_{k}$ and $b_{k}$ as follows:

$$
\begin{aligned}
a_{k}=\frac{1}{2 \pi^{3}}\left(\int_{0}^{\pi} \mathrm{e}^{-\frac{1}{2}\left(\bar{x}^{2}-2\left(\frac{2 \pi}{6}\right) \bar{x}+\frac{4 \pi^{2}}{18}\right)} \cos (k \bar{x}) \mathrm{d} \bar{x}\right. \\
\left.+\int_{\pi}^{2 \pi} \mathrm{e}^{-\frac{1}{2}\left(\bar{x}^{2}-2\left(\frac{4 \pi}{6}\right) \bar{x}+\frac{16 \pi^{2}}{18}\right)} \cos (k \bar{x}) \mathrm{d} \bar{x}\right)
\end{aligned}
$$

By recalling $I_{1}$ and $I_{2}$ from Equations (5) and (6) respectively, we can re-write Equation (7) as follows:

$$
\begin{gathered}
a_{k}=\frac{1}{2 \pi^{3}}\left(\frac{I_{1}}{k}(\sin (k \pi)-\sin (0))+\right. \\
\left.\frac{I_{2}}{k}(\sin (k 2 \pi)-\sin (k \pi))\right) \\
a_{k}=0
\end{gathered}
$$

and

$$
\begin{array}{r}
b_{k}=\frac{1}{2 \pi^{3}}\left(\int_{0}^{\pi} \mathrm{e}^{-\frac{1}{2}\left(\bar{x}^{2}-2\left(\frac{2 \pi}{6}\right) \bar{x}+\frac{4 \pi^{2}}{18}\right)} \sin (k \bar{x}) \mathrm{d} \bar{x}\right. \\
\left.+\int_{\pi}^{2 \pi} \mathrm{e}^{-\frac{1}{2}\left(\bar{x}^{2}-2\left(\frac{4 \pi}{6}\right) \bar{x}+\frac{16 \pi^{2}}{18}\right)} \sin (k \bar{x}) \mathrm{d} \bar{x}\right)
\end{array}
$$

$$
b_{k}=\frac{1}{2 \pi^{3}}\left(\frac{I_{1}}{k}\left(1-(-1)^{k}\right)+\frac{I_{2}}{k}\left(\cos (-1)^{k}-(-1)^{2 k}\right)\right)
$$

Similarly, we obtain the expression for computing membership function in the overlap region of Gaussian Fuzzy sets (i.e., intersection of the Gaussian Fuzzy sets) as follows:

$$
f(\bar{x})=\frac{a_{0}}{2}+\sum_{k=1}^{n}\left(a_{k} \cos (k w \bar{x})+b_{k} \sin (k w \bar{x})\right)
$$


where

$$
\frac{a_{0}}{2}=\frac{1}{2 \pi}\left(\int_{\frac{2 \pi}{3}}^{\pi} \frac{1}{\sqrt{2 \pi}} \mathrm{e}^{-\left(\frac{1}{2} \bar{x}+2\left(\frac{-4 \pi}{6}\right) \bar{x}+\frac{16 \pi^{2}}{18}\right)} \mathrm{d} \bar{x}+\int_{\pi}^{\frac{4 \pi}{3}} \frac{1}{\sqrt{2 \pi}} \mathrm{e}^{-\left(\frac{1}{2} \bar{x}+2\left(\frac{-2 \pi}{6}\right) \bar{x}+\frac{4 \pi^{2}}{18}\right)} \mathrm{d} \bar{x}\right)
$$

By invoking Equation (3), we can express Equation (13) as:

$$
\frac{a_{0}}{2}=\frac{1}{2 \pi}\left\{\begin{array}{l}
0.5 * \sqrt{2 \pi}\left[\operatorname{erf}\left(\sqrt{0.5} * 2 \pi+\frac{\left(\frac{-4 \pi}{6}\right)}{\sqrt{0.5}}\right)-\operatorname{erf}\left(\sqrt{0.5} * \frac{2 \pi}{3}+\frac{\left(\frac{-4 \pi}{6}\right)}{\sqrt{0.5}}\right)\right] \\
+0.5 * \sqrt{2 \pi}\left[\operatorname{erf}\left(\sqrt{0.5} * \frac{4 \pi}{3}+\frac{\left(\frac{-2 \pi}{6}\right)}{\sqrt{0.5}}\right)-\operatorname{erf}\left(\frac{\left(\frac{-2 \pi}{6}\right)}{\sqrt{0.5}}\right)\right]
\end{array}\right\}
$$

From Equation (14), we define $J_{1}$ and $J_{2}$ as:

$$
J_{1}=0.5 * \sqrt{2 \pi}\left[\operatorname{erf}\left(\sqrt{0.5} * 2 \pi+\frac{\left(\frac{-4 \pi}{6}\right)}{\sqrt{0.5}}\right)-\operatorname{erf}\left(\sqrt{0.5} * \frac{2 \pi}{3}+\frac{\left(\frac{-4 \pi}{6}\right)}{\sqrt{0.5}}\right)\right]
$$

and

$$
J_{2}=0.5 * \sqrt{2 \pi}\left[\operatorname{erf}\left(\sqrt{0.5} * \frac{4 \pi}{3}+\frac{\left(\frac{-2 \pi}{6}\right)}{\sqrt{0.5}}\right)-\operatorname{erf}\left(\frac{\left(\frac{-2 \pi}{6}\right)}{\sqrt{0.5}}\right)\right]
$$

Coefficients $a_{k}$ and $b_{k}$ are then computed as follows:

$$
a_{k}=\frac{1}{\pi}\left(\int_{\frac{2 \pi}{3}}^{\pi} \frac{1}{\sqrt{2 \pi}} \mathrm{e}^{-\left(\frac{1}{2} \bar{x}^{2}+2\left(\frac{-4 \pi}{6}\right) \bar{x}+\frac{16 \pi^{2}}{18}\right)} \cos (k \bar{x}) \mathrm{d} \bar{x}+\int_{\pi}^{\frac{4 \pi}{3}} \frac{1}{\sqrt{2 \pi}} \mathrm{e}^{-\left(\frac{1}{2} \bar{x}^{2}+2\left(\frac{-2 \pi}{6}\right) \bar{x}+\frac{4 \pi^{2}}{18}\right)} \cos (k \bar{x}) \mathrm{d} \bar{x}\right)
$$

Upon substituting $J_{1}$ and $J_{2}$ from Equations (15) and (16) respectively, we can re-write Equation (17) as:

$$
a_{k}=\frac{1}{\pi k}\left\{J_{2} \sin \left(\frac{k 4 \pi}{3}\right)-J_{1} \sin \left(\frac{k 2 \pi}{3}\right)\right\}
$$

and

$$
b_{k}=\frac{1}{\pi k}\left\{J_{1}\left(\cos \left(\frac{k 2 \pi}{3}\right)-\cos (k \pi)\right)+J_{2}\left(\cos (k \pi)-\cos \left(\frac{k 4 \pi}{3}\right)\right)\right\}
$$

\subsection{Fourier Series Representation for \\ Triangular Membership Function}

The Fourier series representation for computing the grade of membership of the intersection of triangular Fuzzy sets (i.e. triangular pulses) is given by:

$$
f(\bar{x})=\frac{a_{0}}{2}+\sum_{k=1}^{n}\left(a_{k} \cos (k \bar{x})+b_{k} \sin (k \bar{x})\right)
$$

where

$$
\frac{a_{0}}{2}=\frac{1}{4}
$$

For the case $k$ odd,

$$
f(\bar{x})=\frac{1}{4}-\sum_{k=1}^{N} \frac{4(-1)^{\frac{k-1}{2}}}{\pi^{2} k^{2}} \sin (k \bar{x})
$$

and for the case $k$ even

$$
f(\bar{x})=\frac{1}{4}+\sum_{k=1}^{N} \frac{4}{\pi^{2} k^{2}}\left((-1)^{\frac{k}{2}}-1\right) \cos (k \bar{x})
$$

Similarly, the Fourier series representation for the union of triangular Fuzzy sets (i.e. polygonal waveform) is given by: 


$$
G(\bar{x})=\frac{a_{o}}{2}+\sum_{k=1}^{\infty}\left[a_{k} \cos (k \bar{x})+b_{k} \sin (k \bar{x})\right]
$$

where

$$
\frac{a_{0}}{2}=\frac{1}{2}+\frac{\gamma_{0}}{4}
$$

for the case $k$ odd,

$$
G(\bar{x})=\left(\frac{1}{2}+\frac{\gamma_{0}}{4}\right)-\sum_{k=1}^{N} \frac{4 \gamma_{0}}{\pi^{2} k^{2}} \cos (k \bar{x})
$$

while, for the case $k$ even,

$$
G(\bar{x})=\left(\frac{1}{2}+\frac{\gamma_{0}}{4}\right)+\sum_{k=1}^{N}\left(\left(8-4 \gamma_{0}\right)(-1)^{\frac{k}{2}}+4 \gamma_{0}-8\right) \cos (k \bar{x})
$$

We note that $\gamma_{0}$ is the point of overlap of the two adjoining triangular Fuzzy sets. Thus, $\gamma_{0}$ represents the maximum grade of membership of the intersection of the triangular Fuzzy sets. In compliance with the requirements of the membership function of Fuzzy set, in respect of the intersection, we normalize $f(x)$ as follows:

$$
f(\bar{x})=\frac{f(x)}{\gamma_{0}}=1
$$

where $\gamma_{0}=\max \left(f\left(x_{\text {INTERECTION }}\right)\right)$. i.e. maximum grade of membership for the intersection of triangular Fuzzy sets.

\section{Systems Design and Implementation}

We briefly describe the development of a "Fuzzy controller" to measure temperature and pressure, and produce some output that can represent input to other sub-s ystems or systems. Itemised below are some of the de- tails of systems design and the implementation of the Fuzzy Controllers. The electrical circuit is presented in Figure 1, while the corresponding photo-image of the device is presented in Figure 2.

The circuit in Figure 1 consists of the following major hardware components:

a) Microchip 40-Pin Enhanced Flash PIC16F877A Microcontrollers

b) LM35D precision integrated-circuit temperature sensor

c) MPX4115A piezoresistive pressure sensor, and

d) LCM-S01602DSF/C Liquid Crystal Display (HD 44780-compliant LCD)

There are only four units of the PIC16F877A Microcontrollers deployed in the circuit. Each Microcontroller is configured with XT 4MHz Crystal. Moreover, the circuit incorporates the LCM-S01602DSF/C Liquid Crystal Display (LCD) output unit capable of displaying $2 \times 16$ characters.

The four (4) Microcontrollers are grouped into two functional sections namely:

a) Section 1: Temperature

This section consists of two (2) Microcontrollers. Microcontroller \#1 executes the Program code for temperature input from the LM35D Sensor; it also conditions and convert signals to digital form, and computes grade of membership of the Gaussian Fuzzy sets. Similarly, Microcontroller \#2 executes the corresponding program code for temperature input from the LM35D Sensor, digitises the signals, and computes membership grades of the triangular Fuzzy sets.

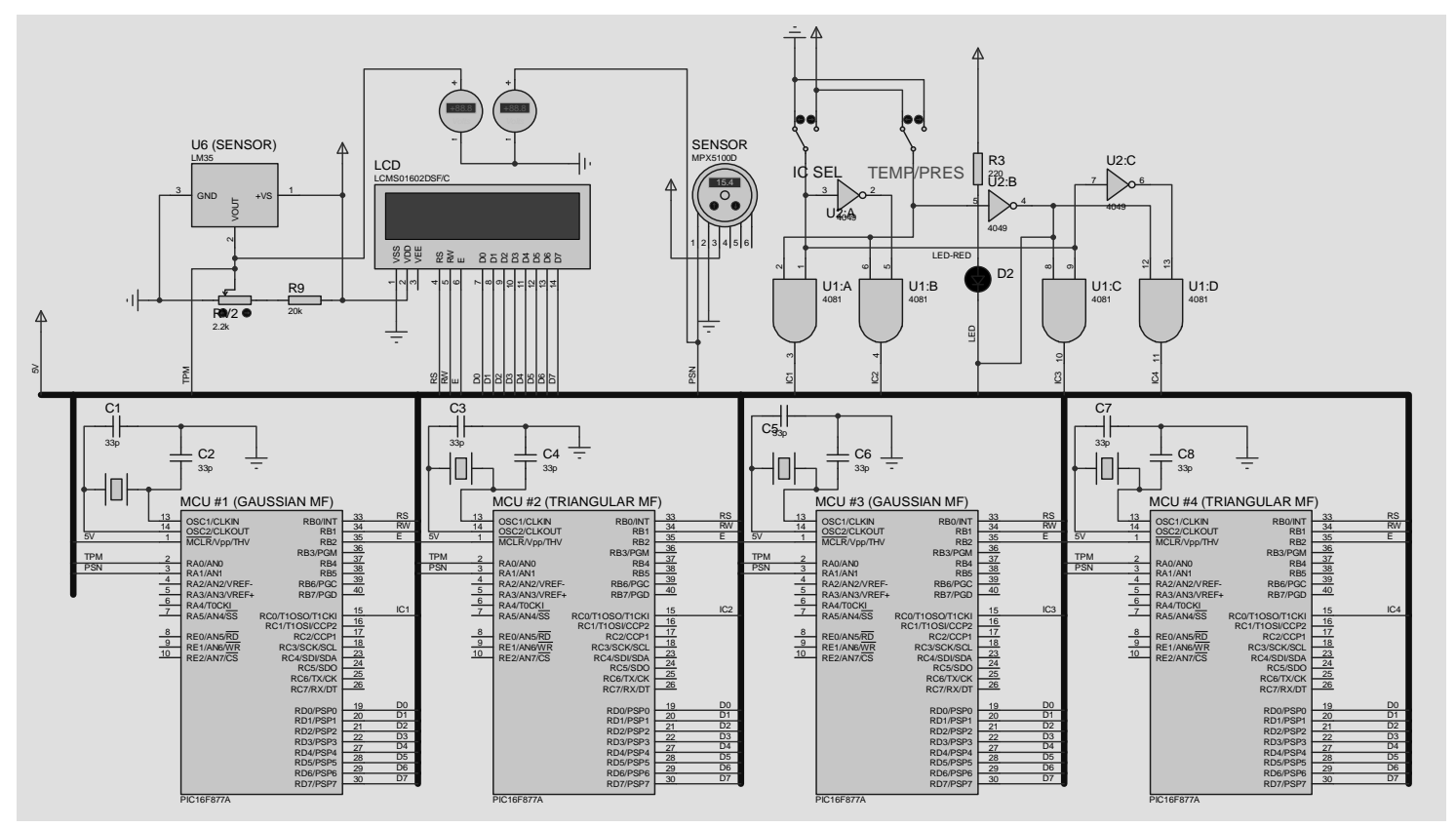

Figure 1. Electrical circuit of the fuzzy controller. 


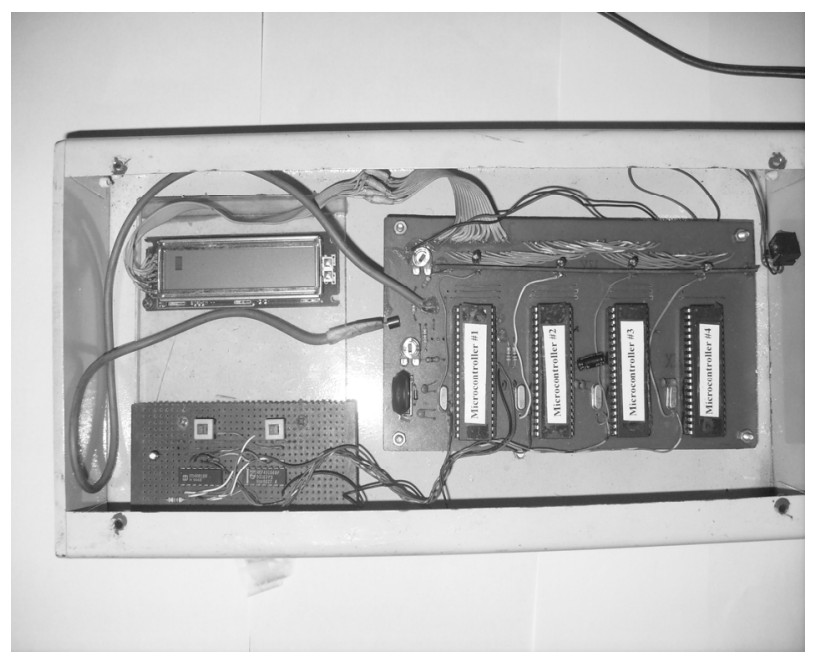

Figure 2. Photo image of the fuzzy controller device.

\section{b) Section 2: Pressure}

This section consists of two (2) additional Microcontrollers to handle the pressure readings from the MPX 4115A Sensor. Microcontroller \#3 computes grade of membership of the Gaussian Fuzzy sets, while the Microcontroller \#4 computes the grade of membership of the triangular Fuzzy sets.

Switching between Sections 1 and 2 is achieved with the Switch labelled TEMP/PRES; while switching between the two Microcontrollers in each Section is achieved with the Switch labelled IC SEL.

\subsection{Use of Fourier Series Representations in the Fuzzy Controllers}

We note that the Program code for the implementation of the Fuzzy controller is written in HITECH ANSI C Language and programmed onto the Microcontrollers using the Microchip PICSTART Plus Programmer.

\subsection{Working Principle of the Fuzzy Controller}

The Fuzzy controller starts by obtaining the real temperature/pressure value and executes the Program code for temperature/pressure input. The Fuzzy Controller conditions and converts the input signal to digital form. The conversion result is subsequently passed to the Function in the Program code that does further processing of the result, computes the grade of membership (i.e. Gaussian or triangular) based on the Fourier representation and relates this value to appropriate linguistic value. The final output (i.e. Very Low, Low, Low Normal, Normal, High Normal, High, Very High) and the corresponding input value from the sensor, which is converted to characters, are then displayed on the LCD.

Sample Fuzzy rules for the Fuzzy Controller for the case of union of Gaussian Fuzzy sets are presented be- low:

IF $((\mathrm{a} 0<=\mathrm{t})$ AND $(\mathrm{t}<\mathrm{a} 1)$ AND MF $<=0.3))$ THEN

Output $=$ "Very Low"

IF $((\mathrm{a} 1<=\mathrm{t})$ AND $(\mathrm{t}<\mathrm{a} 2)$ AND MF $>0.3))$ THEN

Output $=$ "Low";

IF $((\mathrm{a} 2<=\mathrm{t})$ AND $(\mathrm{t}<\mathrm{a} 3)$ AND MF $>0.3))$ THEN Output $=$ "Low Normal"

IF $((\mathrm{a} 3<=\mathrm{t})$ AND $(\mathrm{t}<\mathrm{m})$ AND MF $<=0.3))$ THEN

Output $=$ "Normal"

IF $((\mathrm{m}<=\mathrm{t})$ AND $(\mathrm{t}<\mathrm{a} 4)$ AND MF $<=0.3))$ THEN

Output $=$ "Normal"

IF $((\mathrm{a} 4<=\mathrm{t})$ AND $(\mathrm{t}<\mathrm{b} 2)$ AND MF $>0.3))$ THEN

Output $=$ "High Normal"

IF $((\mathrm{b} 2<=\mathrm{t})$ AND $(\mathrm{t}<\mathrm{b} 3)$ AND MF $>0.3))$ THEN

Output $=$ "High"

IF $((\mathrm{b} 3<=\mathrm{t})$ AND $(\mathrm{t}<=\mathrm{b} 4)$ AND MF $<=0.3))$ THEN

Output $=$ "Very High"

where:

MF Computed grade of membership

$\mathrm{t} \quad$ Temperature value

a0 $\cdots$ a 4 Data points in the first Fuzzy set

b0 $\cdots$ b4 Data Points in the second Fuzzy set

$\mathrm{m} \quad$ Data value at the point of overlap of

the two adjoining Fuzzy sets

For the purpose of linguistic analysis or classification in the Fuzzy plane, we chose 0.3 as the baseline grade of membership.

\subsection{System Flowchart}

We present the system flowchart for the operations of the Fuzzy Controller in Figure 3.

\section{Discussion of Sample Results Obtained from Device for Temperature Measurements}

We present in Table 1, sample results obtained from the Fuzzy Controller device for temperature measurements. The linguistic classifications are based on Gaussian and triangular membership functions for same range of temperature measurements. We have used a baseline membership grade of 0.3 . The observed differences in the band for linguistic classifications indicate effect of approximation errors. Whereas, for example, $44^{\circ} \mathrm{C}-46^{\circ} \mathrm{C}$ is classified as Normal on the basis of Gaussian membership function, $44^{\circ} \mathrm{C}-46^{\circ} \mathrm{C}$ is not classified as belonging to any linguistic class on the basis of triangular membership function. Similar disparities in linguistic classifications are noted in the other data ranges.

For mission-critical applications, such wrong classifycations may have adverse effects on operational and control decisions. For example, a decision rule that would have related to Normal linguistic class, would by virtue of wrong classifications, be related to others. 


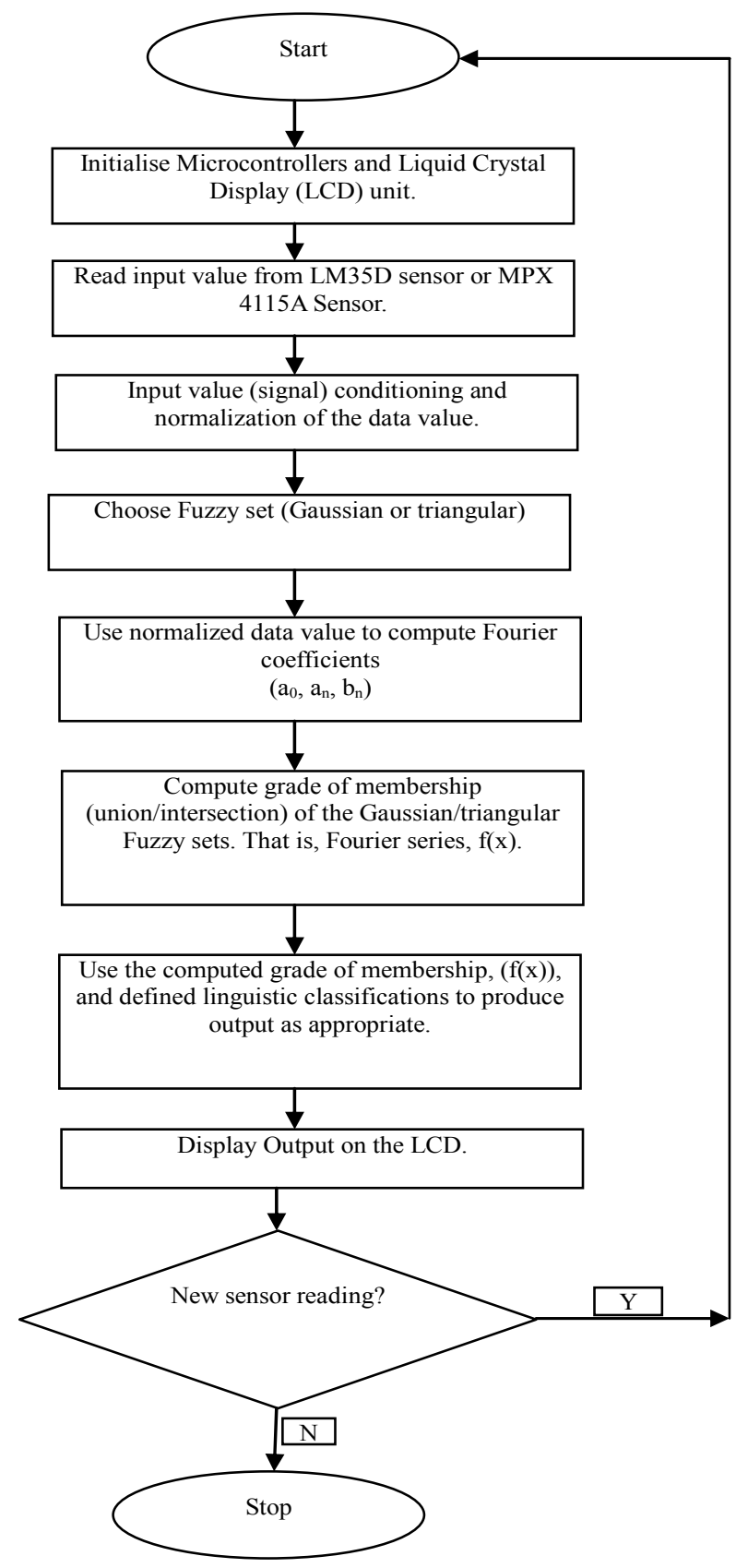

Figure 3. System flowchart.

\section{Summary and Conclusions}

Fuzzy logic is very relevant in machine, process or systems control, and particularly as a means of making machines more capable and responsive by resolving intermediate categories in between states hitherto classified on bivalent logic. In recent years, the use of Fuzzy set theory has been popularised for handling overlap domains in control engineering but this has mostly been in the context of triangular membership functions. In actual practice however, such domains are hardly triangular and
Table 1. Results_-Linguistic classification.

\begin{tabular}{|c|c|c|c|c|}
\hline $\begin{array}{c}\mathrm{T} \\
\left({ }^{\circ} \mathrm{C}\right)\end{array}$ & $\begin{array}{c}\text { Gaussian } \\
\text { Membership } \\
\text { Function } \mathrm{f}(\mathrm{x}) \\
\text {-Union of } \\
\text { Fuzzy sets }\end{array}$ & $\begin{array}{c}\text { Linguisitic } \\
\text { classification } \\
\text { based on Gaus- } \\
\text { sian Member- } \\
\text { ship Function }\end{array}$ & $\begin{array}{l}\text { Linguisitic clas- } \\
\text { sification base- } \\
\text { don Triangular } \\
\text { Membership } \\
\text { Function }\end{array}$ & $\begin{array}{c}\text { Triangular } \\
\text { Membership } \\
\text { Function } \mathrm{f}(\mathrm{x}) \\
\text {-Union of } \\
\text { Fuzzy sets }\end{array}$ \\
\hline 20 & 0.111125036 & \multirow{2}{*}{$\begin{array}{l}\text { Very Low } \\
(\mathrm{MF}<=0.3)\end{array}$} & \multirow{2}{*}{$\begin{array}{l}\text { Very Low } \\
(\mathrm{MF}<=0.3)\end{array}$} & 0.00533707 \\
\hline 21 & 0.222743982 & & & 0.082072208 \\
\hline 22 & 0.332605036 & \multirow{11}{*}{$\begin{array}{c}\text { Low } \\
(\mathrm{MF}>0.3)\end{array}$} & \multirow{2}{*}{$\begin{array}{l}\text { No linguistic } \\
\text { classification }\end{array}$} & 0.163304225 \\
\hline 23 & 0.438975173 & & & 0.245415925 \\
\hline 24 & 0.54017644 & & \multirow{9}{*}{$\begin{array}{c}\text { Low } \\
(\mathrm{MF}>0.3)\end{array}$} & 0.326837778 \\
\hline 25 & 0.634612418 & & & 0.40862068 \\
\hline 26 & 0.720793412 & & & 0.490380506 \\
\hline 27 & 0.79735994 & & & 0.571886187 \\
\hline 28 & 0.863104191 & & & 0.653809756 \\
\hline 29 & 0.916989073 & & & 0.73530292 \\
\hline 30 & 0.958164566 & & & 0.81705902 \\
\hline 31 & 0.985981141 & & & 0.898952519 \\
\hline 32 & 1 & & & 0.979741815 \\
\hline 33 & 1 & \multirow{11}{*}{$\begin{array}{c}\text { Low-Normal } \\
(\text { MF }>0.3)\end{array}$} & \multirow{11}{*}{$\begin{array}{c}\text { Low-Normal } \\
(\mathrm{MF}>0.3)\end{array}$} & 1 \\
\hline 34 & 0.985981141 & & & 0.959996217 \\
\hline 35 & 0.958164566 & & & 0.918978777 \\
\hline 36 & 0.916989073 & & & 0.878081149 \\
\hline 37 & 0.863104191 & & & 0.837379693 \\
\hline 38 & 0.79735994 & & & 0.796377493 \\
\hline 39 & 0.720793412 & & & 0.755647716 \\
\hline 40 & 0.634612418 & & & 0.714763085 \\
\hline 41 & 0.54017644 & & & 0.673863999 \\
\hline 42 & 0.438975173 & & & 0.633164403 \\
\hline 43 & 0.332605036 & & & 0.592101584 \\
\hline 44 & 0.222743982 & \multirow{3}{*}{$\begin{array}{c}\text { Normal } \\
(\mathrm{MF}<=0.3)\end{array}$} & \multirow{3}{*}{$\begin{array}{l}\text { No linguistic } \\
\text { classification }\end{array}$} & 0.551480941 \\
\hline 45 & 0.111125036 & & & 0.513252964 \\
\hline 46 & 0.222743982 & & & 0.551760132 \\
\hline 47 & 0.332605036 & \multirow{11}{*}{$\begin{array}{c}\text { High-Normal } \\
(\mathrm{MF}>0.3)\end{array}$} & \multirow{11}{*}{$\begin{array}{c}\text { High-Normal } \\
\text { (MF > 0.3) }\end{array}$} & 0.592363279 \\
\hline 48 & 0.438975173 & & & 0.633427333 \\
\hline 49 & 0.54017644 & & & 0.675010158 \\
\hline 50 & 0.634612418 & & & 0.715023007 \\
\hline 51 & 0.720793412 & & & 0.755916334 \\
\hline 52 & 0.79735994 & & & 0.796640786 \\
\hline 53 & 0.863104191 & & & 0.837642549 \\
\hline 54 & 0.916989073 & & & 0.878351756 \\
\hline 55 & 0.958164566 & & & 0.919233939 \\
\hline 56 & 0.985981141 & & & 0.960273135 \\
\hline 57 & 1 & & & 1.000259219 \\
\hline 58 & 1 & \multirow{11}{*}{$\begin{array}{c}\text { High } \\
(\mathrm{MF}>0.3)\end{array}$} & \multirow{9}{*}{$\begin{array}{c}\text { High } \\
(\mathbf{M F}>0.3)\end{array}$} & 0.979220042 \\
\hline 59 & 0.985981141 & & & 0.898408762 \\
\hline 60 & 0.958164566 & & & 0.816541304 \\
\hline 61 & 0.916989073 & & & 0.734765832 \\
\hline 62 & 0.863104191 & & & 0.653282651 \\
\hline 63 & 0.79735994 & & & 0.571359212 \\
\hline 64 & 0.720793412 & & & 0.489844469 \\
\hline 65 & 0.634612418 & & & 0.408099566 \\
\hline 66 & 0.54017644 & & & 0.326300678 \\
\hline 67 & 0.438975173 & & \multirow{2}{*}{$\begin{array}{l}\text { No linguistic } \\
\text { classification }\end{array}$} & 0.244889464 \\
\hline 68 & 0.332605036 & & & 0.162781266 \\
\hline 69 & 0.222743982 & \multirow{2}{*}{$\begin{array}{l}\text { Very High } \\
(\mathrm{MF}<=\mathbf{0 . 3})\end{array}$} & \multirow{2}{*}{$\begin{array}{l}\text { Very High } \\
(\mathrm{MF}<=0.3)\end{array}$} & 0.081513341 \\
\hline 70 & 0.111125036 & & & 0.005348055 \\
\hline
\end{tabular}


in fact for most engineering applications are usually Gaussian and sometimes cosine. In this paper, we presented Fourier series representation for the systematic computation of membership functions for Gaussian and triangular Fuzzy sets. We also presented the development of a "Fuzzy Controller" to measure temperature and pressure and produce output that can represent input to additional sub-systems or systems. By way of comparative analysis, it is shown that triangular approximation of Gaussian membership function in Fuzzy control can lead to wrong linguistic classification(s) which may have adverse effects on operational and control decisions. The development of the Fuzzy controller device clearly demonstrates that the proposed technique can indeed be incorporated in engineering systems for the dynamic and systematic computation of grade of membership in the overlap and non-overlap regions of Fuzzy sets; and thus provides a basis for the design of embedded Fuzzy Controller for mission critical applications.

\section{REFERENCES}

[1] L. A. Zadeh, "Outline of a New Approach to the Analysis of Complex Systems and Decision Processes," IEEE Transaction on Systems, Man, and Cybernetics, Vol. SMC-3, No. 1, 1973, pp. 28-44. doi:10.1109/TSMC.1973.5408575

[2] R. E. Bellman and L. A. Zadeh, "Decision-Making in a Fuzzy Environment," Management Sciences, Vol. 17, No. 4, 1970, pp. 141-164. doi:10.1287/mnsc.17.4.B141

[3] H. R. Berenji and P. Khedkar, "Clustering in Product Space for Fuzzy Inference," 2nd IEEE International Conference on Fuzzy Systems, San Francisco, 1993, pp. 14021407.

[4] D. Ruan and P. F. Fantoni (Eds.), "Power Plant Surveillance and Diagnostics-Applied Research with Artificial Intelligence," Springer, Heidelberg, 2002.

[5] V. O. S. Olunloyo and A. M. Ajofoyinbo, "Fuzzy-Stochastic Maintenance Model: A Tool for Maintenance Optimization," International Conference on Stochastic Models in Reliability, Safety, Security and Logistics, Beer Sheva, 15-17 February 2005, pp. 266-271.

[6] J. E. Araujo, S. A. Sandri and E. E. N Macau, "A New Class of Adaptive Fuzzy Control System Applied in Industrial Thermal Vacuum Process," Proceedings of 8th IEEE International Conference on Emerging Technologies and Factory Automation, Vol. 1, 2001, pp. 426-431.

[7] R. Marinke, and E. Araujo, "Neuro-Fuzzy Modeling for Forecasting Future Dynamical Behaviors of Vibration Testing in Satellites Qualification," 59th International Astronautical Congress, Glasgow, 2008 (pre-print).

[8] P. C. Moura, L. Rodrigues and E. Araujo, "A Fuzzy System Applied to Sputtering Glass Production," Proceedings of Simpósio Brasileiro de Automação Inteligente (SBAI), Florianópolis, 2007, CD (in Portuguese).

[9] J. B. Savkovic-Stevanovic, "Fuzzy Logic Control Sys- tems Modelling," International Journal of Mathematical Models and Methods in Applied Sciences, Vol. 3, No. 4, 2009, pp. 327-334.

[10] X. Ji and W. Wang, "A Neural Fuzzy System for Vibration Control in Flexible Structures," Intelligent Control and Automation, Vol. 2, 2011, pp. 258-266. doi:10.4236/ica.2011.23031

[11] V. O. S. Olunloyo, A. M. Ajofoyinbo and A. B. Badiru, "NeuroFuzzy Mathematical Model for Monitoring Flow Parameters of Natural Gas," Applied Mathematics and Computation, Vol. 149, No. 3, 2004, pp. 747-770. doi:10.1016/S0096-3003(03)00177-2

[12] V. O. S. Olunloyo and A. M. Ajofoyinbo, "A New Approach for Treating Fuzzy Sets' Intersection and Union: A Basis for Design of Intelligent Machines," 5th International Conference on Intelligent Processing and Manufacturing of Materials, California, 19-23 July 2005, Proceedings in CD-ROM.

[13] P. J. King and E. H. Mamdani, "The Application of Fuzzy Control Systems to Industrial Processes," Automatica, Vol. 13, No. 3, 1977, pp. 235-242. doi:10.1016/0005-1098(77)90050-4

[14] H. J. Zimmermann, "Fuzzy Set Theory and Its Applications," 2nd Edition, Kluwer Academic Publishers, Boston, 1991.

[15] T. J. Ross, "Fuzzy Logic with Engineering Applications," John Wiley \& Sons Ltd, Chichester, 2007.

[16] N. Watanabe, "Statistical Methods for Estimating Membership Functions," Japanese Journal of Fuzzy Theory and Systems, Vol. 5, No. 4, 1979, pp. 833-846.

[17] I. B. Turksen, "Measurement of Membership Functions and Their Acquisition," Fuzzy Sets and Systems, Vol. 40, No. 1, 1991, pp. 5-38. doi:10.1016/0165-0114(91)90045-R

[18] D. L. Meredith, C. L. Karr and K. Krishnakumar, "The Use of Genetic Algorithms in the Design of Fuzzy Logic Controllers," 3rd Workshop on Neural Networks, Auburn, 1992, pp. 549-545.

[19] C. Karr, "Design of an Adaptive Fuzzy Logic Controller Using a Genetic Algorithm," Proceeding of 4th International Conference on Genetic Algorithms, San Mateo, 1991, pp. 450-457.

[20] M. A. Lee and H. Takagi, "Integrating Design Stages of Fuzzy Systems, Using Genetic Algorithms," Second IEEE International Conference on Fuzzy Systems, Vol. 1, 1993, pp. 612-617. doi:10.1109/FUZZY.1993.327418

[21] T. J. Ross, "Fuzzy Logic with Engineering Applications," John Wiley \& Sons Ltd, Chichester, 2007.

[22] V. O. S. Olunloyo, A. M. Ajofoyinbo, and A. B. Badiru, "An Alternative Approach for Computing the Union and Intersection of Fuzzy Sets: A Basis for Design of Robust Fuzzy Controller," Proceedings of 2008 Conference of World Scientific and Engineering Academy and Society, University of Cambridge, 20-24 February 2008, pp. 301308 (Best Student Paper).

[23] A. M. Ajofoyinbo, "Representation and Encoding of 
Fuzziness in Engineering Systems: The Case of Fuzzy Controllers," Ph. D. Thesis, University of Lagos, Nigeria, 2008, unpublished.

[24] V. O. S. Olunloyo, A. M. Ajofoyinbo and O. Ibidapo-Obe, "Design and Implementation of Embedded Fuzzy Controllers Based on Fourier Computation of Membership Functions," Proceedings of the 8th World Scientific and
Engineering Academy and Society International Conference on Electronics, Hardware, Wireless and Optical Communications, University of Cambridge, 21-23 February 2009, pp. 133-142 (Best Paper of the Conference).

[25] I. Abramowitz and I. A. Stegun, "Handbook of Mathematical Functions," Dover Publications Inc., New York, 1964. 